\title{
Properties of wood-plastic composites made of milled particleboard and polypropylene
}

\author{
Cezary Gozdecki • Arnold Wilczyński • \\ Marek Kociszewski · Stanisław Zajchowski
}

Received: 1 October 2013/Published online: 11 October 2014

(C) The Author(s) 2014. This article is published with open access at Springerlink.com

\begin{abstract}
Particles derived from milling three-layer particleboards, with sizes from 0.5 to $3 \mathrm{~mm}$, were used for making composites with polypropylene by an injection moulding method. Maleated polypropylene was used as a coupling agent. The objective of this study was to evaluate the mechanical and physical properties of the composites made from particleboard and polypropylene with respect to the content of particles derived from particleboard and coupling agent addition. Properties of the composites did not differ significantly from those of composites with virgin industrial wood particles used for manufacturing particleboards. Moreover, these properties were comparable with the properties of typical wood-plastic composites with wood flour. Particles derived from milling particleboards have proved to be an effective alternative wood component of wood-plastic composites.
\end{abstract}

\section{Introduction}

Wood-plastic composites (WPCs) have been rapidly developed in recent years due to their numerous advantages. One is the possibility of using recycled materials, both recycled polymers and wood, for WPC manufacturing. Many studies have shown that the properties of WPCs made from recycled polymers, especially from polypropylene and high-density polyethylene, are only slightly

C. Gozdecki $(\bowtie) \cdot$ A. Wilczyński · M. Kociszewski Institute of Technology, Kazimierz Wielki University, Bydgoszcz, Poland

e-mail: gozdecki@ukw.edu.pl

S. Zajchowski

Faculty of Chemical Technology and Engineering, University of Technology and Life Sciences, Bydgoszcz, Poland inferior to those of WPCs made from virgin polymers. Most WPC companies in the United States use recycled polymers (Winandy et al. 2004). The wood component of WPCs is very often made from waste generated by wood industry. Wood flour which is commonly used in WPC as a wood component is mainly produced from sawdust which is the primary waste product of sawmills. Post-consumer wood pallets (Stark 1999) and poles (Kamdem et al. 2004) proved to be a good source of wood flour. The second common wood component in WPCs is recycled wood fibre including newspaper fibre. The usefulness of fibres from old newspapers has been confirmed by Sanadi et al. (1994), English et al. (1996), Ashori and Nourbakhsh (2009), Ashori (2010), Ashori and Sheshmani (2010), Lopez et al. (2012). Ashori and Nourbakhsh (2008) proved that lignocellulosic fibres from old corrugated containers could be considered as a potential filler of WPCs.

In some countries wood waste, like plastic and paper waste, is a major component of municipal solid wastes in landfills. A large part of the wood waste is post-consumer wood-based panels. The volume of these panels generated per year is still growing. In Poland, their annual supply was 490,000 tons in 2002 and is estimated to reach 665,000 tons in 2015 (Ratajczak et al. 2003). The most common wood-based panels are particleboards. Only a small number of recycled particleboards are used for making new particleboards; most of them are destined for landfill or burned. One of the possibilities of recycling these boards is using them for manufacturing WPCs. Kamdem et al. (2004) studied the properties of WPCs made from recycled urea-formaldehyde (UF) resin bonded particleboard and virgin or recycled high-density polyethylene. Particleboards were milled to obtain particleboard flour with a particle size from $0.15 \mathrm{~mm}$ (100 mesh) to $0.6 \mathrm{~mm}(30$ mesh). Compression moulding was used to manufacture 
WPCs with 50:50 particleboard flour-to-plastic weight ratio. For comparison WPCs from virgin pine wood flour were prepared. In general, the mechanical properties of WPCs with particleboard flour were almost the same as those of WPCs with wood flour. The thickness swelling of WPCs containing particleboard flour was much smaller. The properties of WPCs made from recycled particleboard with UF resin as a binder were also investigated by Chaharmahali et al. (2008). They used the sawdust from particleboard sawing and the flour from particleboard milling. The obtained particles were smaller than $0.6 \mathrm{~mm}$ (30 mesh). The sawdust and flour particles were mixed at a ratio of 50:50 by weight. The WPCs were made by compression moulding method using recycled high-density polyethylene and 60:40, 70:30 and 80:20 particleboard particles-to-plastic weight ratio. The mechanical properties of these WPCs were similar to, or in some cases better than those of conventional particleboards.

In previous studies on WPCs made from recycled particleboards (Kamdem et al. 2004; Chaharmahali et al. 2008) only small particles, smaller than $0.6 \mathrm{~mm}$, were used. These WPCs were made by compression moulding method and high-density polyethylene was used as a composite matrix. WPCs can also be produced from large wood particles, larger than $0.6 \mathrm{~mm}$ (30 mesh). These particles contribute to better mechanical properties of WPCs because they usually have a higher length-to-thickness ratio. This was confirmed in the studies on WPCs with virgin industrial wood particles used for manufacturing particleboards (Bledzki and Faruk 2003; Gozdecki et al. 2011, 2012; Kociszewski et al. 2012). In this study, the novel particleboard-polypropylene composite made by injection moulding method was tested. Large particles derived from particleboards containing the UF resin were used to prepare this WPC. The objectives of the study were to evaluate the mechanical and physical properties of these WPCs as affected by (1) particleboard particle content, (2) coupling agent addition, and to compare these properties, (3) with the properties of WPC made from virgin industrial wood particles and (4) with the properties of WPC made from wood flour.

\section{Methods}

\subsection{Materials}

The polypropylene (PP) used in this study was homopolymer Moplen HP648T (Basell Orlen Polyolefins, Poland). Its density was $0.9 \mathrm{~g} / \mathrm{cm}^{3}$, and its melt flow index was $53 \mathrm{~g} / 10 \mathrm{~min}\left(230^{\circ} \mathrm{C} / 2.16 \mathrm{~kg}\right)$. Maleated polypropylene (MAPP) Fusabond P353 (DuPont) with a density of
$0.9 \mathrm{~g} / \mathrm{cm}^{3}$, melt flow index of $470 \mathrm{~g} / 10 \mathrm{~min}\left(190{ }^{\circ} \mathrm{C} / 2.16 \mathrm{~kg}\right)$, and graft degree of $1.4 \%$ was used as a coupling agent.

Three kinds of wood particles (WPs) were used as fillers: recycled wood particles (RWPs), virgin wood particles (VWPs) and wood flour (WF). The RWPs were derived from three-layer particleboards with a density of $0.7 \mathrm{~g} / \mathrm{cm}^{3}$, a thickness of $18 \mathrm{~mm}$, a shelling ratio (the ratio of the thickness of the face layers to the thickness of the core layer) of 40:60, bonded with UF resin using a resin content of $10 \%$ in the face layers and $8 \%$ in the core layer. Pine wood was a raw material of the wood particles of these particleboards. The particleboards were supplied by Kronospan Szczecinek, Poland. The freshly produced industrial particleboards were used because their composition was known. They were milled by a laboratory hammer-mill, and then screened by an analytical sieve shaker (LAB-11-200/UP, EKO-LAB Poland), using 3 and $0.5 \mathrm{~mm}$ sieves. Particles that passed through the $3 \mathrm{~mm}$ sieve and remained on the $0.5 \mathrm{~mm}$ sieve were used as a filler of WPCs.

The VWPs were derived from industrial pine wood particles used for manufacturing three-layer particleboards, from fine particles for the face layers and coarse particles for the core layer. These particles, which were supplied by Kronospan Szczecinek, Poland, were the same as those used for producing particleboards described in the previous paragraph. The fine particles were screened and only those that remained on the $0.5 \mathrm{~mm}$ sieve were used. Regarding the coarse particles, those that passed through the $3 \mathrm{~mm}$ sieve and remained on the $0.5 \mathrm{~mm}$ sieve were used. In order to simulate a similar content of fine and coarse particles as that in particleboards, the mix consisting of $40 \%$ fine particles and $60 \%$ coarse particles was prepared as a filler of WPCs. The WF from softwood, of type Lignocel ${ }^{\circledR}$ BK 40/90 was supplied by J. Rettenmaier \& Söhne GmbH, Rosenberg, Germany.

The fraction analysis of each kind of WPs was performed using three, $100 \mathrm{~g}$ oven dry samples. Each sample was placed on the top sieve (the $2.0 \mathrm{~mm}$ sieve for RWPs

Table 1 Fraction analysis per weight of the wood particles used

\begin{tabular}{llll}
\hline Screen hole size range $(\mathrm{mm})$ & WF $(\%)$ & VWP $(\%)$ & RWP $(\%)$ \\
\hline$<0.1$ & 5.0 & - & - \\
$0.1-0.25$ & 24.5 & - & - \\
$0.25-0.5$ & 65.9 & - & - \\
$0.5-0.75$ & 4.1 & 22.6 & 9.5 \\
$0.75-1.0$ & 0.5 & 22.3 & 19.0 \\
$1.0-1.5$ & - & 19.2 & 31.3 \\
$1.5-2.0$ & - & 20.6 & 34.1 \\
$2.0-3.0$ & - & 15.4 & 6.1 \\
\hline
\end{tabular}



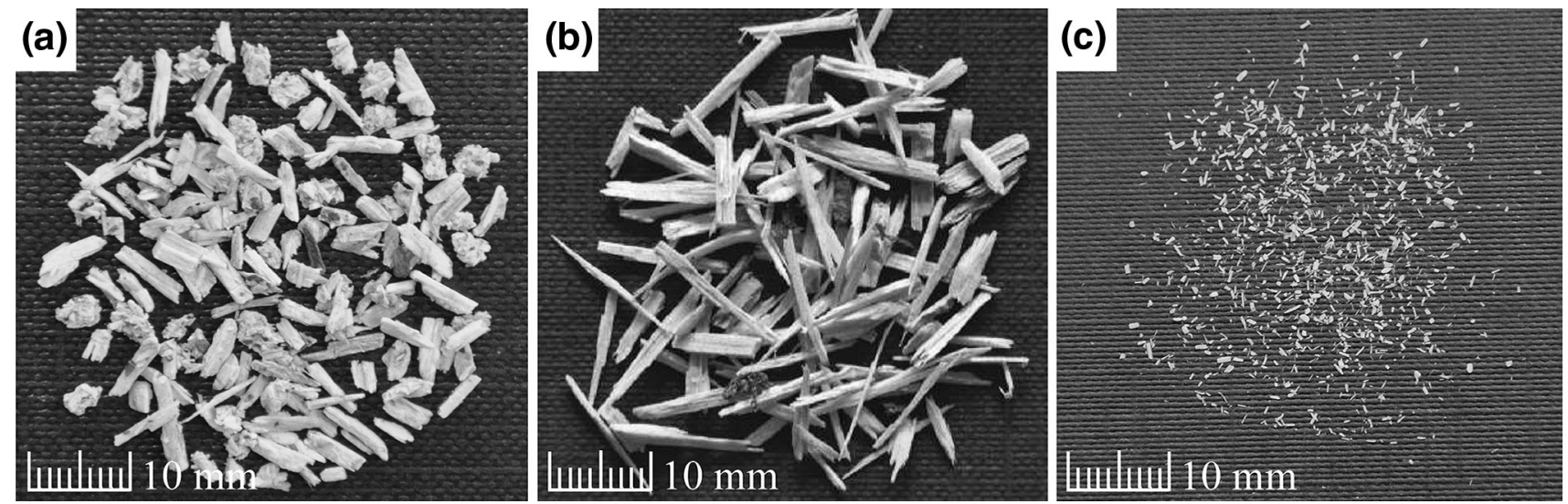

Fig. 1 a RWPs, b VWPs of the fraction 1-2 mm, c WF

and VWPs, and $0.75 \mathrm{~mm}$ sieve for WF) and shaken on an analytical shaker for $20 \mathrm{~min}$. Portions of WP samples remaining on each screen were weighed with an accuracy of $0.01 \mathrm{~g}$ and expressed as the percentage of total sample weight. The WP mass loss during sieve analysis did not exceed $0.2 \%$. The average results of the fraction analysis of three samples of each kind of WPs are presented in Table 1. The RWPs and VWPs of the fraction 1.0-2.0 mm, and the WF are shown in Fig. 1.

\subsection{Wood particle geometry}

The WPs, both the RWPs and VWPs, were measured to determine their geometry. The length, width and thickness of 200 randomly selected RWPs and VWPs for each of the three fractions, $0.5-1.0,1.0-2.0$ and $2.0-3.0 \mathrm{~mm}$ were measured using an optical microscope with a measuring scale. The dimensions of 200 randomly selected WF particles were also measured. The length-to-thickness and width-to-thickness ratios of particles were calculated for each group of particles.

\subsection{Processing}

All WPs and WF were dried at $80{ }^{\circ} \mathrm{C}$ in an air-circulation oven for $24 \mathrm{~h}$ prior to the mixing process in order to achieve a moisture content of less than $3 \%$. WPs, WF, PP and MAPP were dispensed into the hopper using three DSH screw feeders (Hydrapress, Poland) and then mixed in a one-step mixing process in the feed zone of AH- 80 (METALCHEM, Poland) injection moulding machine. The temperature profile was 120 and $180{ }^{\circ} \mathrm{C}$ in feed zone 1 and zone 2 , respectively. The injection pressure time and hold pressure time were 3 and $6 \mathrm{~s}$, respectively. To minimise mechanical degradation of WPs during moulding, the diameter of the injection die was enlarged to $4.5 \mathrm{~mm}$ and the diameter of the sprue bush to $8 \mathrm{~mm}$. The cross section
Table 2 WPC formulations (percent by weight)

\begin{tabular}{lllll}
\hline $\begin{array}{l}\text { WPC } \\
\text { code }\end{array}$ & $\begin{array}{l}\text { Type of } \\
\text { wood particles }\end{array}$ & $\begin{array}{l}\text { Wood } \\
\text { content }\end{array}$ & $\begin{array}{l}\text { PP } \\
\text { content }\end{array}$ & MAPP content \\
\hline RWP-20-3 & RWP & 20 & 77 & 3 \\
RWP-40-3 & RWP & 40 & 57 & 3 \\
RWP-60-3 & RWP & 60 & 37 & 3 \\
RWP-40-0 & RWP & 40 & 60 & 0 \\
VWP-40-0 & VWP & 40 & 60 & 0 \\
WF-40-0 & WF & 40 & 60 & 0 \\
\hline
\end{tabular}

of the runner and the gate was $10 \times 10$ and $6 \times 6 \mathrm{~mm}^{2}$, respectively.

Three kinds of specimens for tensile tests according to EN ISO 527-2 (type 1A), for flexural tests according to EN ISO 178, and for impact strength tests according to EN ISO 179-1 were made. After processing, they were stored in controlled conditions $\left(50 \%\right.$ relative humidity and $\left.20{ }^{\circ} \mathrm{C}\right)$ for 2 weeks prior to testing.

Six experimental WPCs were prepared according to the formulations shown in Table 2.

Four WPCs with the RWPs were produced in order to determine the effect of the WP content and the effect of MAPP. Two WPCs, with the VWPs and the WF, were produced for comparison purposes.

\subsection{Mechanical testing}

Mechanical properties of tested WPCs were evaluated in relation to tensile, flexural, and impact properties. Tensile and flexural tests were performed according to EN ISO 527-2 and EN ISO 178, respectively, using an Instron 3367 machine. The speed of the cross-head was $2 \mathrm{~mm} / \mathrm{min}$. Unnotched Charpy impact strength tests were conducted according to EN ISO 179-1. Ten replicates were run for each test. All tests were performed at room temperature $\left(20{ }^{\circ} \mathrm{C}\right)$ and at constant relative humidity $(50 \%)$. 


\subsection{Water absorption and thickness swelling}

Water absorption and thickness swelling of WPCs were determined using the same specimens as those used in flexural tests. Ten specimens of each WPC formulation were dried in an oven for $24 \mathrm{~h}$ at $100{ }^{\circ} \mathrm{C}$, and the weight and thickness of oven-dried specimens were measured. The specimens were then immersed in distilled water and after $24 \mathrm{~h}$ their weight and thickness were measured. The same procedure was followed after 28 days. The values of water absorption were calculated according to the formula:

Water absorption $(\%)=\frac{W_{t}-W_{0}}{W_{0}} \times 100$

where $W_{t}$ is the specimen weight after a given immersion time, $W_{0}$ is the oven-dried weight. The values of thickness swelling were calculated with the following equation:

Thickness swelling $(\%)=\frac{T_{t}-T_{0}}{T_{0}} \times 100$

where $T_{t}$ is the specimen thickness after a given immersion time, $T_{0}$ is the oven-dried thickness.

\subsection{Statistical analysis}

The obtained data were statistically analyzed using the Statistica version 10. The one-way analysis of variance (ANOVA) was conducted to determine the significance of the effect of RWP content on WPC mechanical properties. Tukey's and Student's test were applied to evaluate the statistical significance between mean values of the properties of WPCs with different WPs and of WPCs made with and without MAPP, respectively.

\section{Results and discussion}

\subsection{WP geometry}

Table 1 presents the fraction analysis of RWPs, VWPs and WF. The RWPs had a greater content of the fractions
1.0-1.5 and 1.5-2.0 $\mathrm{mm}$, whereas the VWPs had a fairly uniform distribution of fractions. The main WF fractions were $0.1-0.25$ and $0.25-0.5 \mathrm{~mm}$. The dimensions of RWPs, VWPs and WF as well as their length-to-thickness and width-to-thickness ratios for several fraction groups are listed in Table 3.

The mean values of RWP length ranged from $2.3 \mathrm{~mm}$ for the fraction $0.5-1.0$ to $5.1 \mathrm{~mm}$ for the fraction 2.0-3.0 mm, while those of VWP length ranged from $3.9 \mathrm{~mm}$ for the fraction $0.5-1.0$ to $16.2 \mathrm{~mm}$ for the fraction 2.0-3.0 $\mathrm{mm}$. Thus, the RWP lengths were much smaller, and as a result the length-to-thickness ratio of RWPs was considerably smaller, on average 4.5 times, than that of VWPs. The mean value of length-to-thickness ratio of WF particles (Table 3) was smaller than that of RWPs. The VWPs were slender, whereas the RWPs and WF particles were thick. The mean values of width-to-thickness ratio of RWPs and WF particles were smaller than those of VWPs.

\subsection{Effect of RWP content}

Figures 2, 3 and 4 show the results for mechanical and physical properties of WPCs made from PP, RWPs and MAPP, and having different content of RWPs. The results of the ANOVA analysis showed that all properties depended significantly on RWP content (Table 4).

The tensile and flexural moduli increased gradually with increasing RWP content from 20 to $60 \%$ (Fig. 2). The increase of the moduli was considerable. These results were expected because the elastic modulus of wood, especially in the grain direction, is higher than that of the polymer. The primary objective of wood as a filler is to increase the stiffness of WPC. Similar results for the WPCs consisting of PP and WF have been reported by Bledzki et al. (2002), Stark and Rowlands (2003) and Tajvidi and Ebrahimi (2003) for the tensile modulus, and Stark and Rowlands (2003) and Cheng et al. (2009) for the flexural modulus.

The tensile and flexural strengths of WPCs decreased moderately when RWP content increased (Fig. 3). A

Table 3 Dimensions, length-to-thickness and width-to-thickness ratios of the WPs

\begin{tabular}{llcllll}
\hline Wood particles & Fraction & Length $(\mathrm{mm})$ & Width $(\mathrm{mm})$ & Thickness $(\mathrm{mm})$ & Length-to-thickness & Width-to-thickness \\
\hline VWP & $0.5<\mathrm{F}<1.0$ & $3.9(1.4)$ & $0.6(0.2)$ & $0.3(0.1)$ & $16.3(4.1)$ & $2.5(0.9)$ \\
& $1.0<\mathrm{F}<2.0$ & $12.2(6.0)$ & $1.4(0.6)$ & $0.6(0.4)$ & $20.2(6.1)$ & $2.6(1.2)$ \\
& $2.0<\mathrm{F}<3.0$ & $16.2(6.4)$ & $2.1(0.9)$ & $0.9(0.5)$ & $20.8(6.2)$ & $2.7(1.1)$ \\
RWP & $0.5<\mathrm{F}<1.0$ & $2.3(0.9)$ & $0.7(0.3)$ & $0.5(0.2)$ & $5.3(2.2)$ & $1.4(0.2)$ \\
& $1.0<\mathrm{F}<2.0$ & $2.9(1.0)$ & $1.3(0.5)$ & $0.9(0.6)$ & $3.5(1.5)$ & $1.4(0.3)$ \\
WF & $2.0<\mathrm{F}<3.0$ & $5.1(2.0)$ & $2.2(0.8)$ & $1.5(0.7)$ & $3.8(1.7)$ & $1.5(0.4)$ \\
\hline
\end{tabular}

Mean values from 200 measurements. Standard deviation in parentheses 


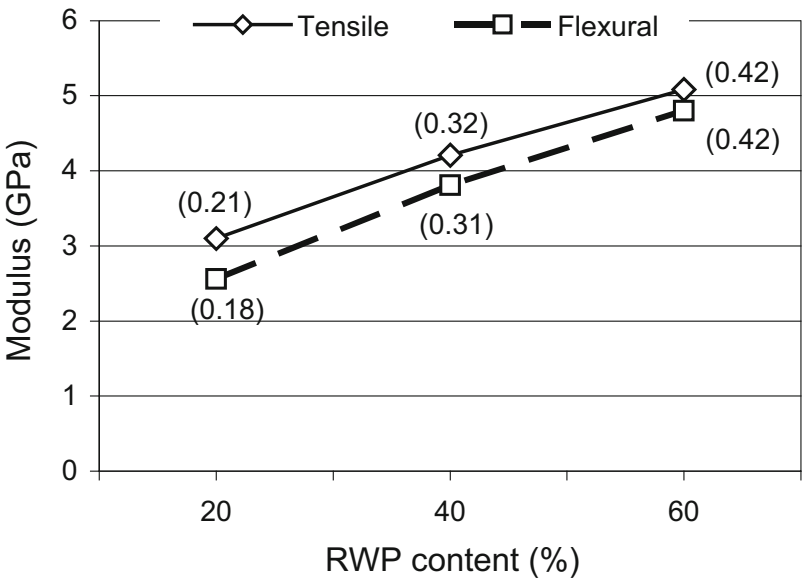

Fig. 2 Effect of RWP content on tensile and flexural moduli of WPCs with MAPP (standard deviation in parentheses)

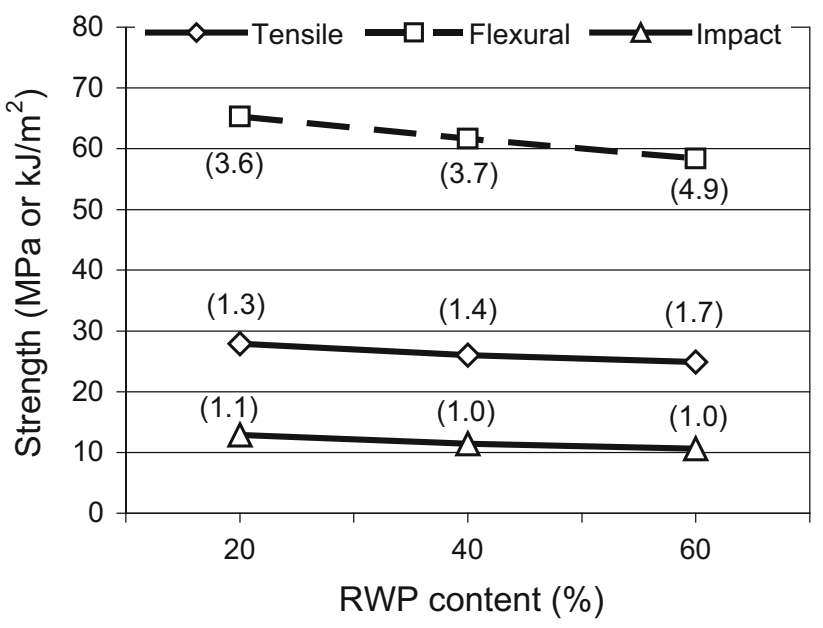

Fig. 3 Effect of RWP content on tensile, flexural and impact strengths of WPCs with MAPP (standard deviation in parentheses)

possible reason for these decreases might be a not quite strong interfacial adhesion between the hydrophilic RWPs and hydrophobic PP matrix, despite the presence of MAPP. As a result, the RWPs were not able to support stresses transferred from the matrix. The slight decrease in the tensile strength with increasing WP content was observed in other studies on WF-PP composites (Zaini et al. 1996; Tajvidi and Ebrahimi 2003; Yang et al. 2006). Cheng et al. (2009) concluded that the flexural strength of WF-PP composite decreased slightly as WP content increased. Bledzki et al. (2002) found that the content of soft WF did not affect the tensile strength of WPC, and Stark and Rowlands (2003) reported that the tensile and flexural strengths slightly increased with increasing WF content. These varied effects of WP content on the strengths of WPCs may be explained by the fact that these strengths depend on various factors including the size of WPs, their length-to-thickness ratio and wood species, processing

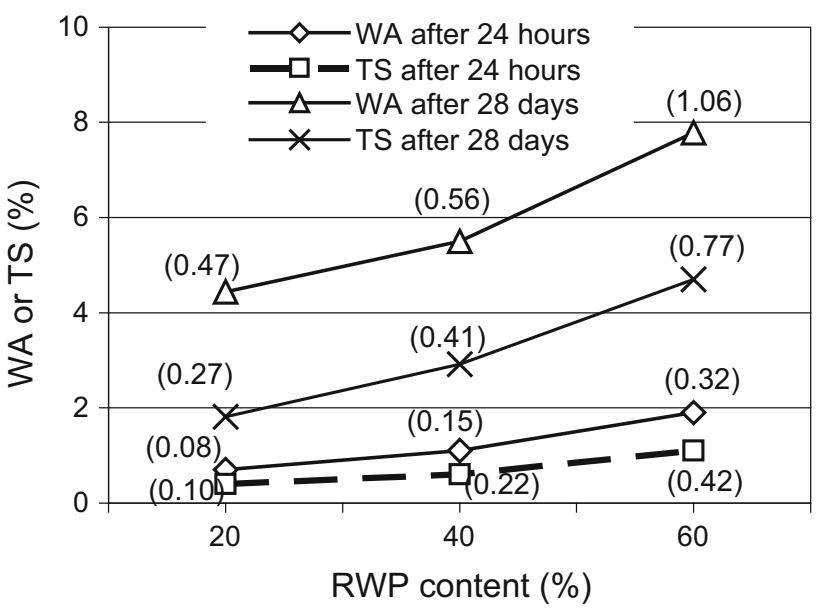

Fig. 4 Effect of RWP content on water absorption (WA) and thickness swelling (TS) of WPCs with MAPP (standard deviation in parentheses)

methods and parameters, and type and amount of coupling agent used.

The impact strength of WPCs decreased moderately, like the tensile and flexural strengths, with increasing RWP content from 20 to $60 \%$ (Fig. 3). The RWPs as a stiff filler provided points of stress concentration. The higher the RWP content the more numerous these points and the lower the impact strength. These results were in fairly good agreement with the data reported by Zaini et al. (1996); Bledzki et al. (2002) and Stark and Rowlands (2003).

The results for the physical properties of WPCs are shown in Fig. 4. The water absorption increased strongly when RWP content increased. The values of water absorption for the WPC with $60 \%$ RWPs were approximately 2.7 times and 1.8 times greater than those for the WPC with $20 \%$ RWPs, for the water absorption after $24 \mathrm{~h}$ and 28 days, respectively. The water absorption in the WPC is due to the wood component because the PP component does not absorb any moisture as a hydrophobic material (Tajvidi and Ebrahimi 2003; Yang et al. 2006; Ashori and Nourbakhsh 2008). The hydroxyl groups inside the cellulose and hemicelluloses attract the water molecules and form hydrogen bonding. As a result, the higher the wood content in the composite, the higher the water absorption. Moreover, due to the porous structure of wood fibres, the composite with higher wood content absorbs more water which penetrates into the pores according to the principle of capillary flow. A similar effect of wood content on WPC water absorption was observed by Bledzki et al. (2002) and Tajvidi and Ebrahimi (2003) for WPCs with WF-PP after $24 \mathrm{~h}$ immersion, and by Khalil et al. (2006) for WPCs with sawdust-PP after 24-h and 20-day immersion. 
Table 4 One-way ANOVA test on the effect of RWP content on WPC mechanical and physical properties ( $p$ values)

\begin{tabular}{|c|c|c|c|c|c|c|c|c|c|}
\hline \multirow[t]{2}{*}{ Variable } & \multirow{2}{*}{$\begin{array}{l}\text { Tensile } \\
\text { modulus }\end{array}$} & \multirow{2}{*}{$\begin{array}{l}\text { Tensile } \\
\text { strength }\end{array}$} & \multirow{2}{*}{$\begin{array}{l}\text { Flexural } \\
\text { modulus }\end{array}$} & \multirow{2}{*}{$\begin{array}{l}\text { Flexural } \\
\text { strength }\end{array}$} & \multirow{2}{*}{$\begin{array}{l}\text { Impact } \\
\text { strength }\end{array}$} & \multicolumn{2}{|c|}{ Water absorption } & \multicolumn{2}{|c|}{ Thickness swelling } \\
\hline & & & & & & $24 \mathrm{~h}$ & 28 days & $24 \mathrm{~h}$ & 28 days \\
\hline $\begin{array}{l}\text { RWP } \\
\text { content }\end{array}$ & $<0.0001 *$ & $<0.0020^{*}$ & $<0.0001 *$ & $0.0113 * *$ & $<0.0007 *$ & $<0.0001^{*}$ & $<0.0001^{*}$ & $<0.0001 *$ & $<0.0001 *$ \\
\hline
\end{tabular}

* Denotes significance at 0.01 . ** Denotes significance at 0.05

The thickness swelling of WPCs, similarly to the water absorption, increased as RWP content increased (Fig. 4). The values of thickness swelling for the WPC with $60 \%$ RWPs were approximately 2.8 times and 2.6 times greater than those for the WPC with $20 \%$ RWPs, for the swelling after $24 \mathrm{~h}$ and 28 days of immersion in water, respectively.

\subsection{Effect of MAPP}

The mechanical properties of WPCs containing $40 \%$ RWPs made with and without MAPP are presented in Figs. 5, 6, 7, 8 and 9. The mean values marked with different capital letters for given property were significantly different at the $5 \%$ significance level. The tensile properties of WPC with MAPP (Figs. 5, 6) were moderately greater than those of WPC without MAPP. The tensile modulus and strength of WPC with MAPP were approximately 10 and $20 \%$ higher, respectively. These increases in the tensile properties were due to better chemical bonding between the RWPs and PP matrix in the presence of MAPP. A similar effect of MAPP on the tensile modulus of WPCs made from PP and WF has been found by Stark (1999), Stark and Rowlands (2003), Bledzki and Faruk (2003), Salemane and Luyt (2006) and Ashori (2010). Furthermore, Bledzki and Faruk (2003) found a similar effect of MAPP on the tensile modulus of WPC made from PP and VWPs. However, the effect of MAPP on tensile strength presented in these studies was stronger than in the current study.

The effect of MAPP on the WPC flexural properties was almost the same as on the tensile properties. The flexural modulus and strength of WPCs with MAPP were approximately 10 and $20 \%$ higher, respectively, than those of non-coupled WPCs (Figs. 7, 8). A similar effect of MAPP on the flexural modulus of WPCs made from PP and WF has been found by Cheng et al. (2009). Bledzki and Faruk (2003) and Stark and Rowlands (2003) observed that this effect was not significant. Regarding the effect of MAPP on the flexural strength of WPCs from PP and WF, Cheng et al. (2009) concluded that it was slight, and Bledzki and Faruk (2003) and Stark and Rowlands (2003) found that it was comparable to the result of this study here. The reason for the different results of these studies might be different sizes and shapes of WPs used to prepare the WPCs. The

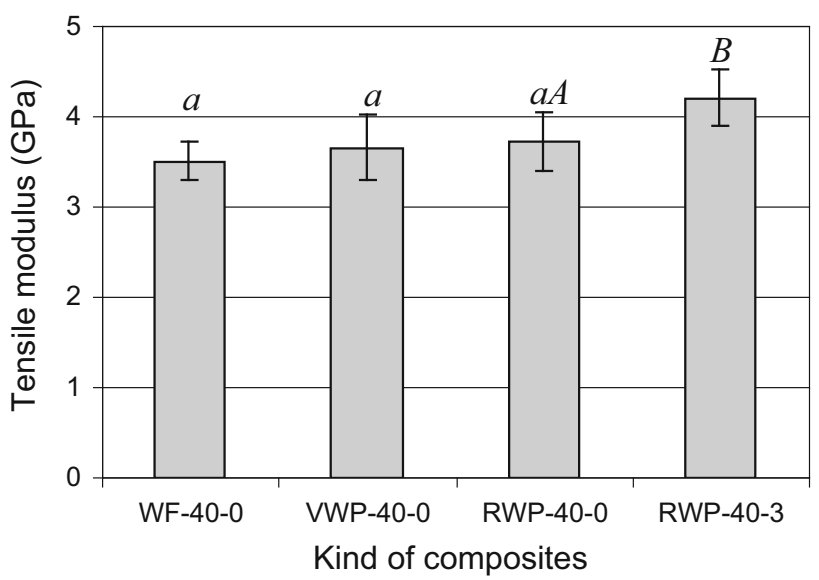

Fig. 5 Tensile modulus of WPCs with $40 \%$ wood content. Means with the same letter are not statistically different; small letters - effect of wood component kind, capital letters-effect of MAPP

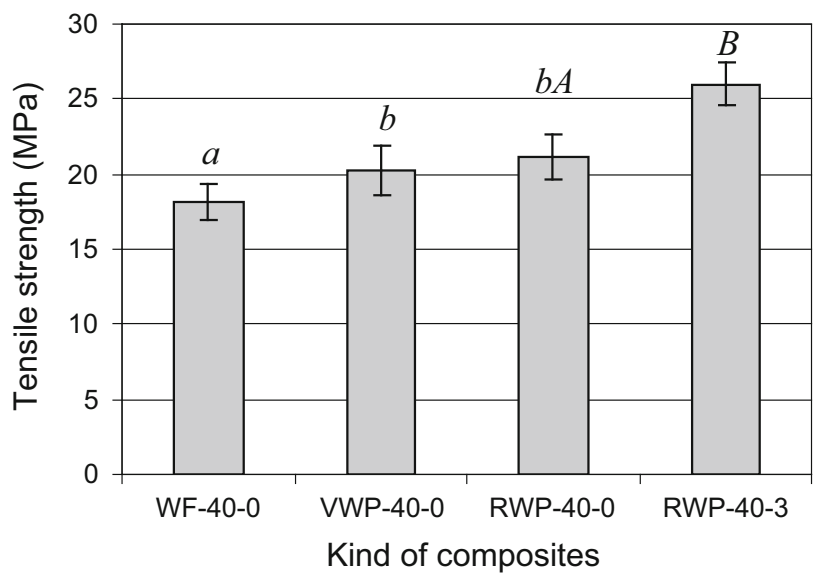

Fig. 6 Tensile strength of WPCs with $40 \%$ wood content. Means with the same letter are not statistically different; small letters-effect of wood component kind, capital letters-effect of MAPP

effect of MAPP on the WPC impact strength was insignificant (Fig. 9).

The water absorption and thickness swelling of WPCs containing $40 \%$ RWPs did not depend significantly on the presence of MAPP (Figs. 10, 11). These results were not confirmed in other studies. Generally, adding MAPP 


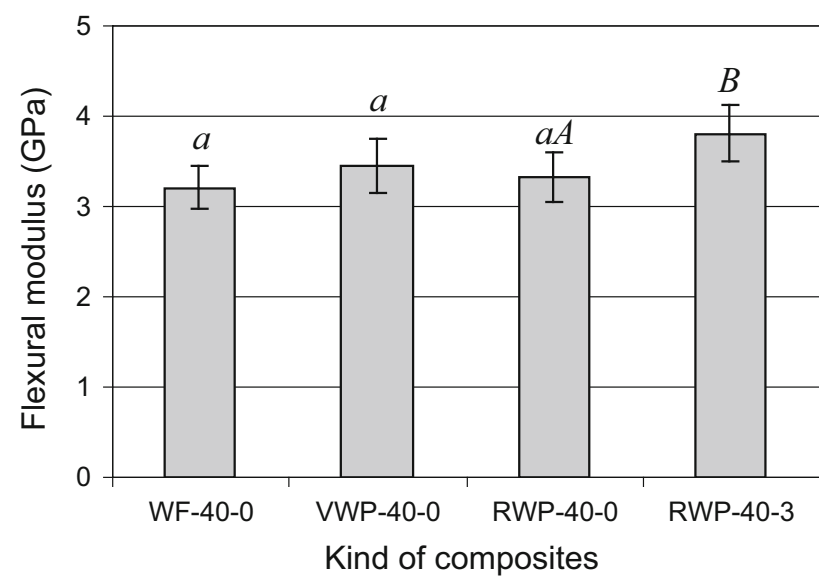

Fig. 7 Flexural modulus of WPCs with $40 \%$ wood content. Means with the same letter are not statistically different; small letters-effect of wood component kind, capital letters-effect of MAPP

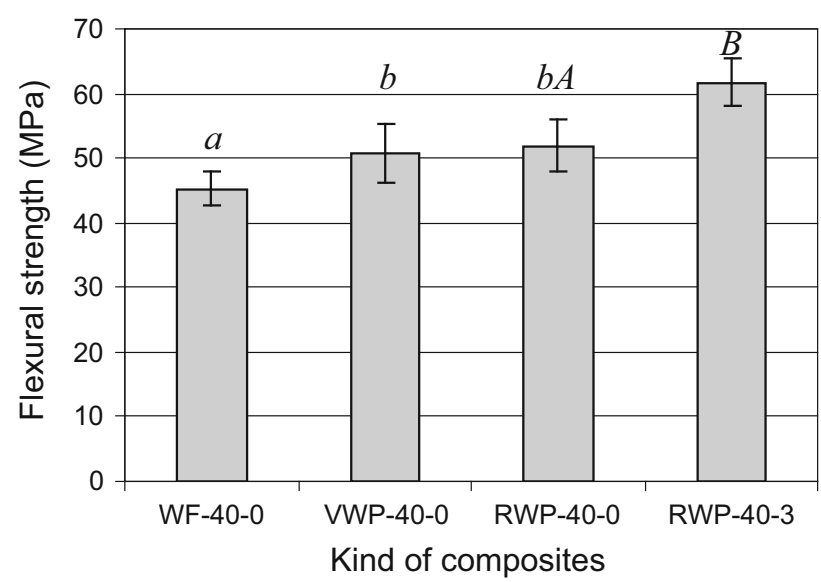

Fig. 8 Flexural strength of WPCs with $40 \%$ wood content. Means with the same letter are not statistically different; small letters-effect of wood component kind, capital letters-effect of MAPP

reduced the water absorption (Bledzki and Faruk 2003; Najafi et al. 2008; Schirp and Stender (2010). Probably, the weaker-than-expected influences of MAPP on the tensile and flexural strengths, and that MAPP did not affect the water absorption and thickness swelling of WPCs with the RWPs may be attributed to the presence of UF resin. Further studies are needed to clarify the role of UF resin contained in the RWPs on the WPC properties.

\subsection{Comparison of the properties of WPCs made from different WPs}

The performance of WPC without MAPP made from RWPs was compared with that of WPC made from VWPs

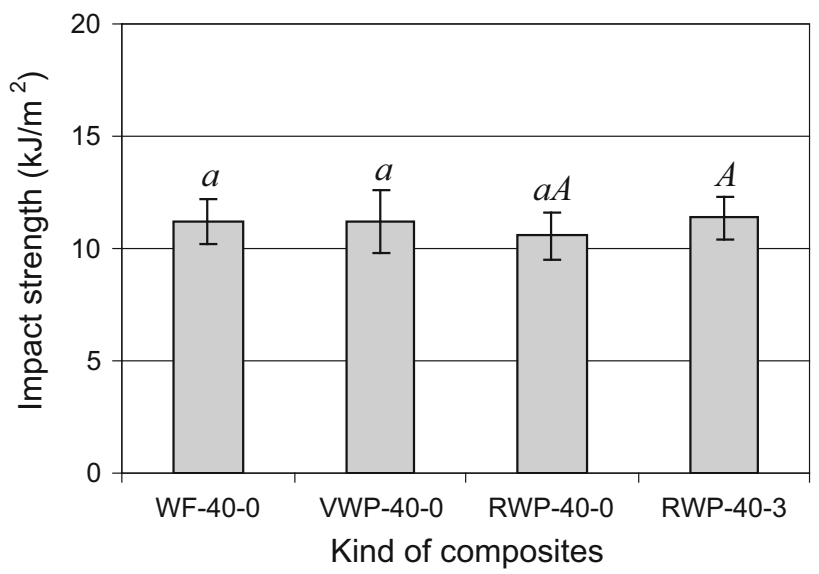

Fig. 9 Impact strength of WPCs with $40 \%$ wood content. Means with the same letter are not statistically different; small letters-effect of wood component kind, capital letters-effect of MAPP

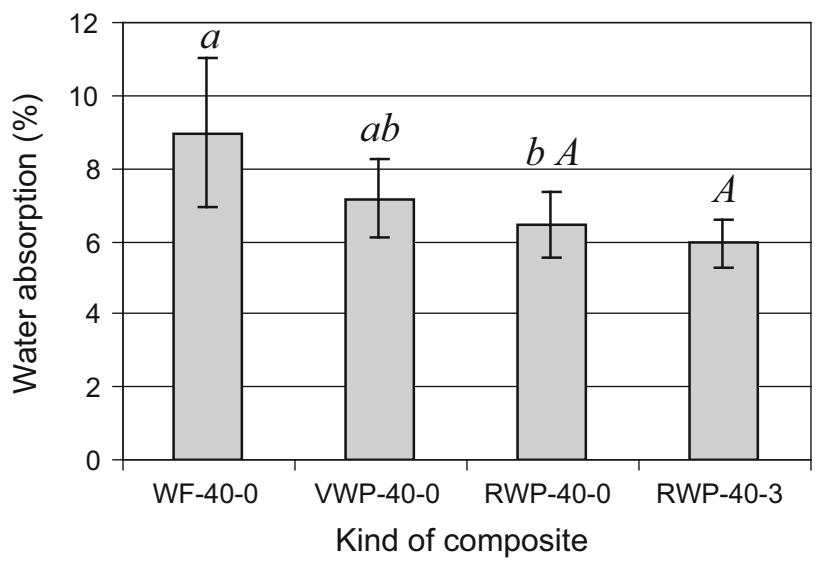

Fig. 10 Water absorption of WPCs with $40 \%$ wood content after 28 days. Means with the same letter are not statistically different; small letters - effect of wood component kind, capital letters-effect of MAPP

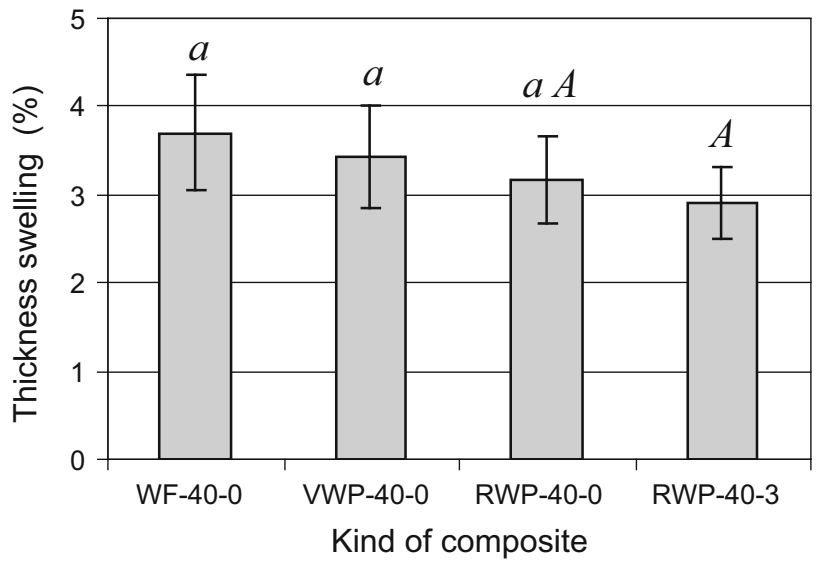

Fig. 11 Thickness swelling of WPCs with $40 \%$ wood content after 28 days. Means with the same letter are not statistically different; small letters-effect of wood component kind, capital letters-effect of MAPP 
(Figs. 5, 6, 7, 8, 9, 10, 11). The mean values marked with the same small letter for given property were not significantly different at the $5 \%$ significance level. There were no statistical differences between the properties of these WPCs. It was expected that the mechanical properties of WPC with the VWPs would be better. The VWPs had much higher length-to-thickness ratio than the RWPs (Table 3) and it should result in improving the WPC mechanical properties (Zaini et al. 1996; Stark and Rowlands 2003; Gozdecki et al. 2012; Kociszewski et al. 2012). Probably, the fact that the mechanical properties of WPC with RWPs were not worse than those of WPC with VWPs may be attributed to the presence of UF resin in the RWPs.

The properties of WPC without MAPP made from RWPs were also compared with those of WPC made from WF (Figs. 5, 6, 7, 8, 9, 10, 11). Among the mechanical properties, the tensile and flexural moduli and the impact strength of compared WPCs did not differ significantly, whereas the tensile and flexural strengths of the WPC with RWPs were greater, approximately by $15 \%$, than those of the WPC with WF. This increase in the strengths may be attributed to higher length-to-thickness ratio of RWPs and the presence of UF resin in the RWPs. These results agreed with Bledzki and Faruk (2003), who concluded that the tensile and flexural moduli of the WPC with chips were almost the same, and the tensile and flexural strengths of that WPC were slightly greater in comparison with the WPC with soft WF. Gozdecki et al. (2012) found that all mechanical properties of the WPC with WPs of the size 1-2 mm were better than those of the WPC with soft WF. The water absorption of the WPC with RWPs was less, by approximately $25 \%$, than that of the WPC with WF, whereas there was no significant difference between the thickness swelling of these WPCs.

\section{Conclusion}

The RWPs derived from milling three-layer particleboards was found to be a good wood material for making composites with PP by an injection moulding method. These particles had sizes from 0.5 to $3 \mathrm{~mm}$, and were shorter and had considerably smaller length-to-thickness ratio than the industrial VWPs used for producing particleboards. Nevertheless, neither the mechanical nor physical properties of WPC with RWPs differed statistically from those of WPC with VWPs. Moreover, the properties of WPC with RWPs were comparable with the properties of typical WPC made from WF. Further studies are needed to clarify the role of UF resin contained in the WPCs with RWPs.

Acknowledgments This work was supported by grant 508011 32/0844 from the Polish Ministry of Science and Higher Education.
The authors would like to thank Kronospan Szczecinek Sp. z o.o. for providing wood material for this study.

Open Access This article is distributed under the terms of the Creative Commons Attribution License which permits any use, distribution, and reproduction in any medium, provided the original author(s) and the source are credited.

\section{References}

Ashori A (2010) Hybrid composites from waste materials. J Polym Environ 18:65-70

Ashori A, Nourbakhsh A (2008) A comparative study on mechanical properties and water absorption behavior of fiber reinforced polypropylene composites prepared by OCC fiber and aspen fiber. Polym Compos 29(5):574-578

Ashori A, Nourbakhsh A (2009) Characteristics of wood-fiber plastic composites made of recycled materials. Waste Manage 29:1291-1295

Ashori A, Sheshmani S (2010) Hybrid composites made from recycled materials: moisture absorption and thickness swelling behavior. Bioresour Technol 101:4717-4720

Bledzki AK, Faruk O (2003) Wood fibre reinforced polypropylene composites: effect of fibre geometry and coupling agent on physico-mechanical properties. Appl Compos Mater 10:365-379

Bledzki AK, Faruk O, Huque M (2002) Physico-mechanical studies of wood fiber reinforced composites. Polym-Plast Technol 41(3):435-451

Chaharmahali M, Tajvidi M, Najafi SK (2008) Mechanical properties of wood plastic composite panels made from waste fiberboard and particleboard. Polym Compos 29(6):606-610

Cheng Q, Wang S, Rials TG, Kit KM, Hansen M (2009) Fabrication optimization of polypropylene composites reinforced with steam-exploded wood flour by wet process. Eur J Wood Prod 67:449-455

English B, Clemons CM, Stark N, Schneider JP (1996) Waste-woodderived fillers for plastics. Forest Products Laboratory, General Technical Report FPL-GTR-91, Madison, p 15

Gozdecki C, Zajchowski S, Kociszewski M, Wilczyński A, Mirowski J (2011) Effect of particle size on mechanical properties of industrial wood particle-polyethylene composites. Polimery 56(5):375-380

Gozdecki C, Wilczynski A, Kociszewski M, Tomaszewska J, Zajchowski S (2012) Mechanical properties of wood-polypropylene composites with industrial wood particles of different sizes. Wood Fiber Sci 44(1):14-21

Kamdem DP, Jiang H, Cui W, Freed J, Matuana LM (2004) Properties of plastic composites made of recycled HDPE and wood flour from CCA-treated wood removed from service. Compos Part A 35:347-355

Khalil HPSA, Shahnaz SBS, Ratnam MM, Ahmad F, Fuaad NAN (2006) Recycle polypropylene (RPP)—wood saw dust (WSD) composites-part 1: the effect of different filler size and filler loading on mechanical and water absorption properties. J Reinforced Plast Comp 25:1291-1303

Kociszewski M, Gozdecki C, Wilczynski A, Zajchowski S, Mirowski J (2012) Effect of industrial wood particle size on mechanical properties of wood-polyvinyl chloride composites. Eur J Wood Prod 70:113-118

Lopez JP, Boufi S, El Mansouri NE, Mutje P, Vilaseca F (2012) PP composites based on mechanical pulp, deinked newspaper and jute strands: a comparative study. Compos Part B 43:3453-3461

Najafi SK, Kiaefar A, Tajvidi M (2008) Effect of bark flour content on the hygroscopic characteristics of wood-polypropylene composites. J Appl Polym Sci 110:3116-3120 
Ratajczak E, Szostak A, Bidzinska G (2003) Used wood in Poland (in Polish). Instytut Technologii Drewna, Poznań

Salemane MG, Luyt AS (2006) Thermal and mechanical properties of polypropylene-wood powder composites. J Appl Polym Sci 100:4173-4180

Sanadi AR, Young RA, Clemons C, Rowell M (1994) Recycled newspaper fibers as reinforcing fillers in thermoplastics: part I-analysis of tensile and impact properties in polypropylene. J Reinfor Plast Compos 13(1):54-67

Schirp A, Stender J (2010) Properties of extruded wood-plastic composites based on refiner wood fibres (TMP fibres) and hemp fibres. Eur J Wood Prod 68:219-231

Stark NM (1999) Wood fiber derived from scrap pallets used in polypropylene composites. Forest Prod J 49(6):39-46

Stark NM, Rowlands RE (2003) Effects of wood fiber characteristics on mechanical properties of wood/polypropylene composites. Wood Fiber Sci 35(2):167-174
Tajvidi M, Ebrahimi G (2003) Water uptake and mechanical characteristics of natural filler-polypropylene composites. J Appl Polym Sci 88:941-946

Winandy JE, Stark NM, Clemons CM (2004) Considerations in recycling of wood-plastic composites. In: Proceedings of 5th global wood and natural fibre composites symposium, Kassel, April 2004, pp 197-205

Yang HS, Kim HJ, Park HJ, Lee BJ, Hwang TS (2006) Water absorption behavior and mechanical properties of lignocellulosic filler-polyolefin bio-composites. Compos Struct 72(4):429-437

Zaini MJ, Fuad MYA, Ismail Z, Mansor MS, Mustafah J (1996) The effect of filler content and size on the mechanical properties of polypropylene/oil palm wood flour composites. Polym Int 40:51-55 